\title{
How Nestling Tree Swallows (Tachycineta bicolor) Integrate their Responses to Hunger and Signalling by Nestmates
}

\author{
Paulo A. M. Marques* $\uparrow$, Marty L. Leonard $\ddagger$, Andrew G. Horn $\ddagger$ \& Adrienne Contastił \\ * Unidade Investigação em Eco-Etologia, ISPA-IU, Lisboa, Portugal \\ $\uparrow$ Museu Nacional de História Natural, Universidade de Lisboa, Lisboa, Portugal \\ + Department of Biology, Dalhousie University, Halifax, NS, Canada \\ $\S$ Department of Biology, University of Saskatoon, Saskatoon, SK, Canada
}

\section{Correspondence}

Andrew G. Horn, Department of Biology, Dalhousie University, Halifax, NS B3H 4J1, Canada.

E-mail: aghorn@dal.ca

Received: September 16, 2010 Initial acceptance: October 21, 2010 Final acceptance: October 21, 2010 (S. Foster)

doi: $10.1111 / j .1439-0310.2010 .01859 . x$

\begin{abstract}
Young animals in a broad range of taxa solicit care from their parents with begging displays, which are used at least partly for competition among brood or litter mates. The effect of other begging offspring on an individual's own begging display varies across studies, however, increasing its intensity in some, but not changing, or even decreasing it, in others. One possible reason for this discrepancy is that the potential pay-off for more intense begging depends not only on how intensely an individual's brood or littermates are begging, but also on how long that individual has been without food. Surprisingly, however, no studies have focused on how begging responses vary when both factors are varied simultaneously. We therefore examined how nestling tree swallows, Tachycineta bicolor, respond to nestmates in relation to both their own hunger levels and the begging intensity of nestmates. During a period of food deprivation, we played focal nestlings parental contact calls either alone (control) or with the begging calls of a nestling deprived of food for 30-50 (low intensity) or 100-110 min (high intensity). Nestlings called for longer in response to the low-intensity playback, but, surprisingly, not in the high-intensity playback, in which they instead delayed the onset of their calling. All these responses to nestmates were independent of how long the responding nestling had been deprived of food. Thus, even in the seemingly intensely competitive environment of a passerine brood, offspring do not necessarily respond to nestmates with escalation. This may be because de-escalation is the best competitive option in some circumstances, or because begging has other functions besides advertisement of individual need and competition over food allocation. Certainly, the results illustrate the need for studies of how nestmate interactions vary across a broad range of contexts.
\end{abstract}

\section{Introduction}

Young animals from burying beetles to domestic pigs produce a conspicuous begging display when soliciting resources from parents (Wright \& Leonard 2002; Smiseth \& Moore 2004; Drake et al. 2008). These widespread displays generally include some combi- nation of vigorous calling, posturing and scrambling for optimal feeding positions, and they are known to regulate both food allocation to individual offspring and overall provisioning rates (Wright $\&$ Leonard 2002). The dominant explanations for the extravagance of these displays are that they are the result of selection for costly, honest signals and/or of 
escalation driven by sibling competition (Johnstone $\&$ Godfray 2002). Both explanations suggest that the intensity of begging displays should reliably reflect offspring state, with offspring generally begging more intensely the needier they are (Johnstone $\delta$ Godfray 2002; see, e.g., Price $\&$ Ydenberg 2002 for exceptions). Indeed, begging does increase with one measure of short-term need, time without food, across a variety of taxa (Wright $\delta$ Leonard 2002; Kilner $\delta$ Hinde 2008).

Begging intensity is also predicted to increase with the number or begging intensity of siblings (Godfray 1995), but here empirical work has yielded conflicting results. In many species, begging intensity does show the predicted increase (Smith \& Montgomerie 1991; Price 1996; Neuenschwander et al. 2003; Madden et al. 2009), but in others it actually decreases (Mathevon \& Charrier 2004; Marques et al. 2006; Bell 2007; Madden et al. 2009). Recent attempts to explain this discrepancy (Brilot \& Johnstone 2002; Johnstone 2004; Madden et al. 2009) suggest it may arise because begging can affect both food allocation (which nestling is fed) and food provisioning (how often food is delivered to the brood as a whole). When begging is used to influence parental food allocation, begging intensity is expected to increase with an increase in the number or begging intensity of siblings, as each offspring attempts to get its own share (Godfray 1995; Johnstone 2004; Madden et al. 2009). When begging serves to stimulate parental food deliveries to the group as a whole, however, then begging intensity might stay constant or even decrease in response to an increase in the number or begging intensity of siblings, because the brood or littermates are already doing the work of stimulating parental returns (Brilot \& Johnstone 2002; Johnstone 2004; Madden et al. 2009).

The begging strategy that individual offspring use should depend on which yields the greatest pay-off at any given time (Forbes 2007). Two factors are likely to affect that pay-off: how long the offspring has been without food, with longer periods increasing the pay-off of competing, and the begging intensity of nestmates, with more intense begging increasing the level of competition but also increasing parental provisioning rate (Forbes 2007). Surprisingly, however, how hunger and the begging intensity of brood or littermates together affect the response of offspring to siblings has never been tested. Indeed, few studies have varied both factors within the same experimental design. Most studies examining the effect of siblings on begging intensity have treated hunger as a nuisance variable, keeping hunger levels constant (e.g., Price 1996; Leonard \& Horn 1998; Leonard et al. 2000) or allowing hunger to vary naturally as parents feed broods of different sizes (e.g., Price 1996; Leonard \& Horn 1998; Neuenschwander et al. 2003; Marques et al. 2006). Some studies have included both hunger and sibling begging in their experimental design, but rather to study begging in relation to long-term condition or competitive ability (e.g., Price et al. 1996; Lotem 1998; Krebs 2001; Bulmer et al. 2007; but see Roulin 2004).

Here, we determine how hunger and the begging intensity of nestmates affect the response of nestling tree swallows, Tachycineta bicolor, to siblings. In this study, we exposed focal nestlings over a period of food deprivation to playbacks of tree swallow nestlings begging at low and high intensities. Like other altricial passerines, tree swallow nestlings give a begging display consisting of posturing, gaping and calling. By various measures, both the visual and the acoustic components of the display intensify with hunger, and both are correlated with food allocation within the nest and provisioning rate, although the effect of begging on allocation and provisioning has only been experimentally demonstrated for begging calls (reviewed in Horn \& Leonard 2008). Begging also varies in response to nestmates; nestlings placed in larger broods or with hungry nestmates posture more intensely (Leonard \& Horn 1998; Leonard et al. 2000) and nestlings call at higher rates when calling together (Leonard \& Horn 2001a). These results suggest that nestling tree swallows escalate their begging in response to nestmates, but none of these experiments manipulated subject hunger and nestmate signalling simultaneously.

\section{Methods}

\section{Study Site and Subjects}

This study was conducted in the Gaspereau Valley of Nova Scotia, Canada between 15 May and 31 July 2007 using a population of tree swallows breeding in nest boxes [study sites described in Leonard 8 Horn (1996)]. To determine nestling age, we checked nest boxes every second day until laying was complete and then again $2 \mathrm{~d}$ before the anticipated hatching date. Nests were then checked daily until hatching was complete.

We weighed nestlings in each of 43 broods ( $\overline{\mathrm{X}}$ $( \pm \mathrm{SD})$ brood size: $5.4 \pm 0.89)$ when nestlings were $6 \mathrm{~d}$ old and banded the three nestlings closest in weight with an individually coloured leg band. The 
following day, the three banded nestlings were removed from the nest, fed a single mouthful of moistened Hartz egg biscuit for birds and transported to the laboratory in a cooler lined with a hot water bottle and towel. Transportation between the nest site and laboratory took no more than $10 \mathrm{~min}$.

\section{Experimental Procedure}

Once at the laboratory, each nestling was placed in a wicker nest cup in one of three identical, randomly assigned nest boxes that were placed in separate rooms. A Genexxa 33-3033 microphone was suspended from the top of each nest box approximately $10 \mathrm{~cm}$ above the nest cup. The microphone was attached to a Canon Optura miniDV digital camera (Mississauga, Ontario, Canada), which records at a sample rate of $44 \mathrm{kHz}$ and sample depth of 16 bits and allows manual adjustment of recording levels, which were kept constant across trials. The camera was attached to a tripod and placed at the open side of the nest box, along with a $2 \mathrm{~W}$ speaker amplifier (Koss hdm $111 \mathrm{BK}$, response $\pm 3 \mathrm{~dB}$ from 100 to $15 \mathrm{kHz}$ ). Each nest box was lined with an electric heating pad that maintained the temperature at $29^{\circ} \mathrm{C}$.

Following a 10-min acclimation period, nestlings were stimulated to beg every $10 \mathrm{~min}$ for $1.5 \mathrm{~h}$ without food (nine test periods), a protocol that is very effective in eliciting begging over extended periods in the laboratory, despite the absence of actual visits by the parent (e.g., Leonard \& Horn 2001b, 2006). The stimulation consisted of one of the following three playback treatments (see details below): (1) Control treatment: parental contact call, used by parents to stimulate begging (Leonard et al. 1997), followed by 15 s of silence; (2) Low-intensity playback: identical to control, except that the $15 \mathrm{~s}$ of silence was replaced by $15 \mathrm{~s}$ of recorded begging calls (12-18 calls/15 s interval) from 6- to 7-d-old tree swallow nestlings that had been deprived of food for 30-50 min, after being fed to satiation; or (3) High-intensity playback: identical to the latter treatment, except that the begging calls (27-33 calls/15 s interval) were from nestlings that had been deprived of food for 100-110 min. Nestlings were randomly assigned to these playback treatments, which were balanced across different rooms. Within a given trial, the same 15-s recording was played in all nine test periods and playbacks in different treatment groups were staggered by approximately one min. Once trials ended, the nestlings were fed moistened egg biscuit and returned to their home nests.
Five stimulus tapes were prepared for each playback treatment using calls recorded during a previous study (Leonard \& Horn 2001b). Each tape consisted of $15 \mathrm{~s}$ of calls taken immediately after individual nestlings were stimulated to call by playback of a parental contact call. Thus, the arrangement of sounds on all the tapes mimicked the sequence of sounds that would naturally occur after a parent arrived at the nest. We prepared five tapes to check that our results were not attributable to the particular tapes we used (Bennington \& Thayne 1994; Wiley 2003). We did this check using initial analyses that included tape and its interaction with treatments in the models described below. These analyses confirmed that treatment effects did not vary significantly across different tapes $\left(F_{8,25}<1.50\right.$, $\mathrm{p}>0.20)$.

\section{Measurement of Begging: Visual Components}

Video clips of each playback session were extracted from the video tapes using iMovie version 2.12 (Apple Computer Inc., Cupertino, CA, USA, 19992002) on a Macintosh G4 computer. An observer blind to the goals of the experiment recorded the following features of the visual component of the begging display: (1) latency to beg [time (s) between the beginning of the parental contact call and the focal nestling raising its head], (2) maximum postural intensity [based on the following scale: 0 (head down, no gaping), 1 (head down, gaping, sitting on tarsi), 2 (head up, gaping, sitting on tarsi), 3 (head up, gaping, neck stretched upward), 4 (head up, gaping, neck stretched upward, body lifted off tarsi), 5 (head up, gaping, neck stretched upward, body lifted off tarsi, wings flapping)] and (3) postural duration [time (s) from the nestling raising its head and gaping until closing its gape and putting its head down].

\section{Measurement of Begging: Acoustic Components}

Audio files were extracted from the video tapes made during each playback session using iMovie version 2.12 as above. We created spectrograms (analysis bandwidth of $67 \mathrm{~Hz}$, display resolution $47 \mathrm{~Hz} \times 1 \mathrm{~ms}$ ) of the calls using Raven 1.2 software (Cornell Laboratory of Ornithology, Ithaca, NY, USA). Comparisons with spectrograms of the original playback calls allowed us to easily distinguish response calls from playback calls. We measured the following features of response calls: (1) latency to calling [time (ms) between the beginning of the 
parental contact call and the nestling's first call], (2) calling rate (number of calls per min) and (3) calling duration [time (ms) from the nestling's first call to its last call]. We measured these particular call features because they are acoustic components of begging that are roughly analogous to the postural components that we measured (latency, intensity and duration).

\section{Statistical Analyses}

We tested for an effect of nestmate signalling and its interaction with deprivation time using a mixed model, in which playback treatment (control, low intensity and high intensity), deprivation time (treated as a continuous variable) and their interaction were fixed effects, and source brood and its interactions with the fixed effects were random effects. Exploratory analyses on both the raw and the transformed (see below) data included a quadratic term for deprivation time, which was never significant and was therefore dropped from the model. Variance components were estimated using restricted maximum likelihood, and tests were implemented in JMP 7.0.1 (SAS Institute Inc. 2007). Some trials failed because nestlings failed to beg or because of equipment failure, so sample sizes vary across analyses. Also, denominator (error) degrees of freedom vary across variables, because of how the analyses adjusted for bias (SAS Institute Inc. 2007). To achieve homogeneous, symmetrical variances in the residuals, transformations were applied as follows: a reciprocal transform to latency to beg, a log transform to postural duration and latency to calling, and a square root transformation to postural intensity and calling duration. Postural intensity is an ordinal measurement, but its distribution after transformation and its correlation with continuous (but harder to measure) measures of begging intensity (Lotem 1998; Leonard et al. 2000) offer support for the parametric assumptions of normality and additivity. Also, non-parametric equivalents of the tests reported here (separate Friedman tests for each effect of interest, using Kendall's tau to measure changes with deprivation time), while less powerful and less appropriate for the present design, produced similar results.

Previous studies have established that except for latency to calling, which we have not previously measured in this species (but see Marques et al. 2008), all visual and acoustic components of begging measured here change in response to food depriva- tion, in the direction of more intense begging with increasing deprivation time (e.g., Leonard $\delta$ Horn 1996, 2001b, 2006). Thus, while we do report the relationships between begging variables and deprivation time, we focus the results on the relationships that are our main interest here, i.e. the effects of nestmate signalling and its interaction with deprivation time effects.

\section{Results}

All visual and acoustic components of begging increased significantly with food deprivation time (Table 1, Fig. 1), except for latency to beg and latency to calling, which did not vary significantly with deprivation time (Table 1, Fig. 1a, d).

More importantly, none of the variables showed significant interactions between playback treatment and time without food (Table 1). Both latency to calling and calling duration, however, varied significantly with playback treatment (Table 1). Specifically, latency to calling was longer in the high-intensity playback treatment compared to the low-intensity playback and control treatments (Fig. 1d), while calling duration was longer in the low-intensity playback treatment than in the other two treatments (Fig. If). None of the other variables differed significantly with playback treatment.

\section{Discussion}

This experiment varied hunger and the begging intensity of nestmates simultaneously, instead of separately, as in most previous studies. Doing so revealed that nestling responses to nestmates were surprisingly independent of their own hunger levels and instead depended mainly on the signalling levels of the nestmates. Moreover, the response to nestmates was more complex than the simple increase or decrease with nestmate begging that has been observed in most other studies. Specifically, nestlings increased calling duration in response to the lowintensity playback, and increased latency to call in response to the high-intensity playback.

\section{Hunger and Response to Nestmates}

The begging intensity of focal nestlings increased in response to food deprivation, but responses did not vary with playback treatment. Thus, our results offer little support for the suggestion that nestlings might assess their own short-term needs in relation to the needs of nestmates and adjust their level of signal- 
Table 1: Results of ANOVA on visual and acoustic components of begging in relation to deprivation time (hunger), playback treatment (control, low-intensity playback, high-intensity playback) and their interaction

\begin{tabular}{|c|c|c|c|c|c|c|c|c|c|}
\hline & \multicolumn{3}{|c|}{ Deprivation time } & \multicolumn{3}{|c|}{ Playback treatment } & \multicolumn{3}{|c|}{ Time $\times$ playback treatment } \\
\hline & $\mathrm{F}$ & $\mathrm{df}$ & $\mathrm{p}$ & $F$ & $\mathrm{df}$ & $\mathrm{p}$ & F & $d f$ & $\mathrm{p}$ \\
\hline \multicolumn{10}{|l|}{ Visual } \\
\hline Latency to beg & 3.57 & 1,27 & 0.07 & 0.23 & 2,52 & 0.79 & 0.35 & 2,422 & 0.70 \\
\hline Postural intensity & 138.68 & 1,25 & $<0.0001$ & 2.63 & 2,50 & 0.08 & 1.33 & 2,399 & 0.26 \\
\hline Postural duration & 68.27 & 1,32 & $<0.0001$ & 3.01 & 2,46 & 0.06 & 0.81 & 2,426 & 0.44 \\
\hline \multicolumn{10}{|l|}{ Acoustic } \\
\hline Latency to calling & 2.73 & 1,9 & 0.13 & 6.42 & 2,19 & 0.0075 & 1.36 & 2, 271 & 0.26 \\
\hline Calling rate & 132.23 & 1,17 & $<0.0001$ & 1.19 & 2,31 & 0.32 & 1.09 & 2,252 & 0.34 \\
\hline Calling duration & 127.37 & 1,8 & $<0.0001$ & 8.11 & 2,30 & 0.0016 & 2.02 & 2,248 & 0.13 \\
\hline
\end{tabular}
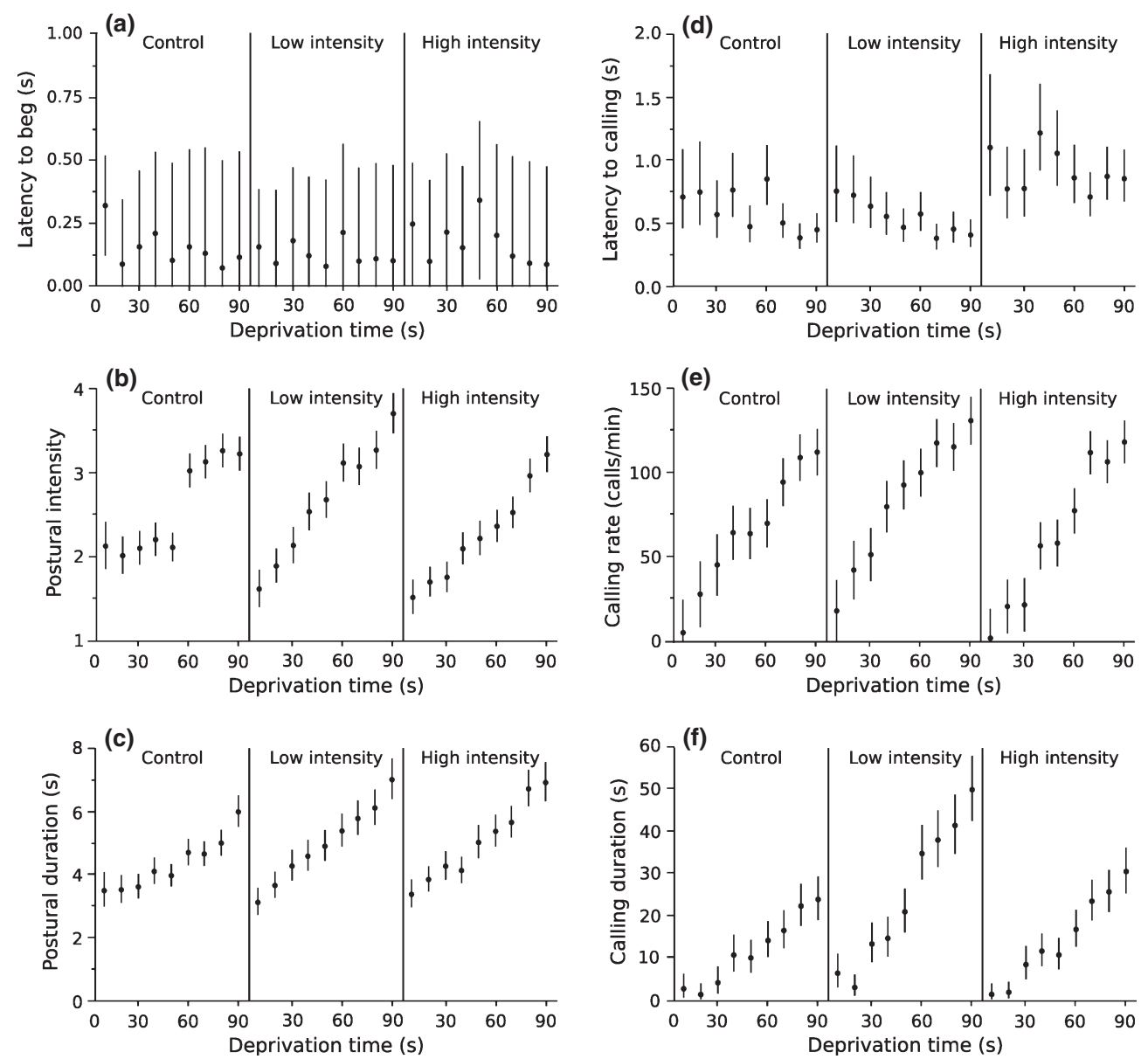

Fig. 1: $(\bar{X}( \pm S E)$ begging measures in relation to deprivation time during control, low-intensity playback and high-intensity playback treatments: (a) latency to beg, (b) postural intensity, (c) postural duration, (d) latency to calling, (e) calling rate and (f) calling duration.

ling accordingly (Godfray 1995; Johnstone \& Roulin 2003). Instead, nestlings simply increased their begging the longer they were without food, with a rate of increase that was independent of the level of signalling by nestmates.
We should note that our failure to detect an interaction between hunger and signalling by nestmates in the present study does not rule out a possible interaction in other situations, particularly when the competitive abilities of nestmates differ. For example, a 
more competitive (e.g. larger) nestling that is only moderately hungry might decrease its begging in response to intensely begging smaller nestmates, either to parasitize their efforts to increase parental provisioning (Johnstone 2004) or to allow the smaller nestmates to be fed and thus increase the large nestling's inclusive fitness (Price \& Ydenberg 2002). In the present study, both the nestlings that provided the playback calls and the focal nestlings were midsized nestlings in their home broods, and thus presumably of similar competitive abilities. There are some indications that the largest and smallest nestlings in tree swallow broods differ in their begging strategies and competitive abilities (e.g. Leonard $\delta$ Horn 200la,b), so the interaction predicted by some theoretical work (e.g. Price \& Ydenberg 2002) and suggested in some empirical studies (e.g. Price 1996) may well apply in such situations.

\section{Begging and Signalling by Nestmates}

We found that calling duration was higher during the low-intensity playback than during the control treatment. That is, in response to low levels of calling by nestmates, focal nestlings called for a longer period of time. This result is consistent with previous studies from several species showing that playback of begging calls stimulates nestlings to call more persistently (e.g. Muller \& Smith 1978; Beecher \& Beecher 1983; Chaiken 1990; Horn \& Leonard 2008).

Surprisingly, however, nestlings did not prolong their calling in response to the higher intensity playback and, in fact, they delayed the onset of their calling compared to the lower intensity and control treatments. Interestingly, postural intensity and duration may have shown a similar peak with the low-intensity playback (Fig. 1), although the significance levels for both these variables are inconclusive (Table 1).

There are several reasons why a nestling might reduce its begging when nestmates beg especially intensely. One possibility is that the nestling holds back on its effort because a nestmate that is begging very intensively is more likely to win the feeding (Roulin 2002; Johnstone 8 Roulin 2003), although if that were the case we would expect nestlings to escalate again as they grew hungrier and thus increasingly likely to win the feeding, which they did not. A second possibility is that the focal nestling holds back because, once its nestmate is begging intensively enough, the nestmate increases overall provisioning rate to the level that the nestling can gain sufficient feedings without having to beg more itself as it did in the low-intensity treatment (Johnstone 2004). It is hard to imagine that this explanation could apply to the seemingly highly competitive environment of passerine broods, but it does appear to explain cases of de-escalation of begging found in a few other bird and mammal species (e.g. Mathevon \& Charrier 2004; Bell 2007; Madden et al. 2009).

Surprisingly, we found no significant playback treatment effects on calling rate, despite a previous study on this study population showing that it increases in response to nestmate signalling (Leonard $\&$ Horn 2001a). One reason for the different results may be that playback was used to present nestmate signalling in the present study, rather than live nestlings, as in the previous studies. Perhaps when nestlings are competing with live, responsive nestmates, they, in effect, goad each other on, resulting in escalations in posturing and call rate that are not stimulated by the unresponsive playback tapes used in the present experiment. Indeed, nestling calling interactions probably depend other factors as well, such as position in the nest (Leonard et al. 2003; Dreiss et al. 2010), that might be revealed by other playback paradigms than the one used here.

\section{Signalling Between Nestmates}

A few previous studies have shown that nestlings call more when nestmates are calling (e.g. Muller $\&$ Smith 1978; Beecher \& Beecher 1983; Chaiken 1990; Horn \& Leonard 2008), but our results additionally show that nestlings adjust their begging in relation to variation in the level of signalling by nestmates. This raises the interesting possibility that begging in this species may not just be a signal to parents, but may be a signal to nestmates, as well. In some species, nestmates appear to negotiate, in effect, over how strongly they should signal, both collectively and individually, to their parents (Roulin 2002). Such signals are thought to occur between feedings, when parents are absent, in several species (Magrath et al. 2010), but there is emerging evidence that negotiation signals might occur when parents are present, as well (Roulin 2004; Roulin et al. 2008). Showing that begging responses are directed at nestmates, as opposed to a side effect of a response to parents, requires showing some specialization in their form or delivery for interacting with nestmates (Horn \& Leonard 2005). Such evidence is not apparent from our current results, but might be revealed by studies of how calls vary in structure and timing from one call to the next during nestmate interactions (as in Roulin et al. 2009; Dreiss et al. 2010). 


\section{Conclusion}

We conclude that nestling tree swallows may either increase or decrease their acoustic responses to nestmates depending on the begging intensity of the nestmates, but largely independently of their own hunger levels. This pattern of response may reflect the dual allocation and provisioning functions of begging, although it will take further work to test this explanation. Such complexities of nestmate interactions are best teased apart by studies that attend to variation in the individual components of begging (as in, e.g., Price 1996; Kilner 2002), rather than test for escalation of overall begging intensity, which has been the focus of most studies of nestmate interactions to date.

\section{Acknowledgements}

This work was supported by a Natural Sciences and Engineering Research Council of Canada Discovery Grant to M.L.L. and Fundação para a Ciência e Tecnologia grants SFRH/34846/2007 and SFRH/17350/ 2004 to P.A.M.M. We thank Alex Dorland for help in the field, the Coldwell, Hines and Minor families for continued access to their properties. The research reported in this paper conformed to both federal and institutional requirements for the use of animals in research (Dalhousie University's Committee on Laboratory Animals Protocol \# 06-044).

\section{Literature Cited}

Beecher, I. M. \& Beecher, M. D. 1983: Sibling recognition in bank swallows. Z. Tierpsychol. 62, 145-150.

Bell, M. B. V. 2007: Cooperative begging in banded mongoose pups. Curr. Biol. 17, 17-721.

Bennington, C. C. \& Thayne, W. V. 1994: Use and misuse of mixed model analysis of variance in ecological studies. Ecology 75, 717-722.

Brilot, B. O. \& Johnstone, R. A. 2002: Cost, competition and information in communication between relatives. J. Theor. Biol. 217, 331-340.

Bulmer, E., Celis, P. \& Gil, D. 2007: Parent-absent begging: evidence for sibling honesty and cooperation in the spotless starling (Sturnus unicolor). Behav. Ecol. 19, $279-284$.

Chaiken, M. 1990: The ontogeny of antiphonal calling in European starlings. Dev. Psychobiol. 23, 233-246.

Drake, A., Fraser, D. \& Weary, D. M. 2008: Parent-offspring resource allocation in domestic pigs. Behav. Ecol. Sociobiol. 62, 309-319.

Dreiss, A., Lahlah, N. \& Roulin, A. 2010: How siblings adjust sib-sib communication and begging signals to each other. Anim. Behav. 80, 1049-1055.
Forbes, S. 2007: Sibling symbiosis in nestling birds. Auk 124, $1-10$.

Godfray, H. C. J. 1995: Signalling of need between parents and young: parent-offspring conflict and sibling rivalry. Am. Nat. 146, 1-24.

Horn, A. G. \& Leonard, M. L. 2005: Nestling begging as a communication network. In: Animal Communication Networks (McGregor, P., ed.). Cambridge Univ. Press, Cambridge, pp. 170-190.

Horn, A. G. \& Leonard, M. L. 2008: Acoustic interactions in broods of nestling birds (Tachycineta bicolor). J. Comp. Psychol. 122, 298-304.

Johnstone, R. A. 2004: Begging and sibling competition: how should offspring respond to their rivals? Am. Nat. 163, 388-406.

Johnstone, R. A. \& Godfray, H. C. J. 2002: Models of begging as a signal of need. In: The Evolution of Nestling Begging: Competition, Cooperation and Communication (Wright, J. \& Leonard, M. L., eds). Kluwer Academic, Dordrecht, The Netherlands, pp. 1-20.

Johnstone, R. A. \& Roulin, A. 2003: Sibling negotiation. Behav. Ecol. 14, 780-786.

Kilner, R. M. 2002: The evolution of complex begging displays. Models of begging as a signal of need. In: The Evolution of Nestling Begging: Competition, Cooperation and Communication (Wright, J. \& Leonard, M. L., eds). Kluwer Academic, Dordrecht, The Netherlands, pp. 87-106.

Kilner, R. M. \& Hinde, C. A. 2008: Information warfare and parent-offspring conflict. Adv. Study Behav. 38, 283-336.

Krebs, E. A. 2001: Begging and food distribution in crimson rosella (Platycercus elegans) broods: why don't hungry chicks beg more? Behav. Ecol. Sociobiol. 50, 20-30.

Leonard, M. L. \& Horn, A. 1996: Provisioning rules in tree swallows. Behav. Ecol. Sociobiol. 38, 341-347.

Leonard, M. L. \& Horn, A. 1998: Need and nestmates affect begging in tree swallows. Behav. Ecol. Sociobiol. 42, 431-436.

Leonard, M. L. \& Horn, A. 2001a: Dynamics of calling by tree swallow (Tachycineta bicolor) nestmates. Behav. Ecol. Sociobiol. 50, 430-435.

Leonard, M. L. \& Horn, A. 2001b: Acoustic signalling of hunger and thermal state by nestling tree swallows. Anim. Behav. 61, 87-93.

Leonard, M. L. \& Horn, A. 2006: Age-related changes in signalling of need by nestling tree swallows (Tachycineta bicolor). Ethology 112, 1020-1026.

Leonard, M. L., Fernandez, N. \& Brown, G. 1997: Parental calls and nestling behaviour in tree swallows. Auk 114, 668-672.

Leonard, M. L., Horn, A. G., Gozna, A. \& Ramen, S. 2000: Brood size and begging intensity in nestling birds. Behav. Ecol. 11, 196-201. 
Leonard, M. L., Horn, A. G. \& Parks, E. 2003: The role of posturing and calling in the begging display of nestling birds. Behav. Ecol. Sociobiol. 54, 188-193.

Lotem, A. 1998: Differences in begging behaviour between barn swallow, Hirundo rustica, nestlings. Anim. Behav. 55, 809-818.

Madden, J. R., Kunc, H. P., English, S., Manser, M. B. \& Clutton-Brock, T. C. 2009: Calling in the gap: competition or cooperation in littermates' begging behaviour? Proc. R. Soc. Lond. B Biol. Sci. 276, 1255-1262.

Magrath, R. D., Haff, T. M., Horn, A. G. \& Leonard, M. L. 2010: Calling in the face of danger? How predation risk affects acoustic communication by parent birds and their offspring Adv. Study Behav. 41, 187-253.

Marques, P. A. M., Márquez, R. \& Vicente, L. M. 2006: Brood size and nestling vocal begging behaviour in the Spanish Sparrow Passer hispaniolensis. Ardea 94, 203-210.

Marques, P. A. M., Vicente, L. \& Márquez, R. 2008: Iberian azure-winged magpie Cyanopica (cyana) cooki nestlings begging calls: call characterization and hunger signalling. Bioacoustics 18, 133-149.

Mathevon, N. \& Charrier, I. 2004: Parent-offspring conflict and the coordination of siblings in gulls. Proc. R. Soc. Lond. B Biol. Sci. 271, S145-S147.

Muller, R. E. \& Smith, D. G. 1978: Parent-offspring interactions in zebra finches. Auk 95, 485-495.

Neuenschwander, S., Brinkhof, M. W. G., Kölliker, M. \& Richner, H. 2003: Brood size, sibling competition, and the cost of begging in great tits (Parus major). Behav. Ecol. 14, 457-462.

Price, K. 1996: Begging as competition for food in yellow-headed blackbirds. Auk 113, 963-967.

Price, K. \& Ydenberg, R. 2002: State-dependent begging with asymmetries and costs: a genetic algorithm approach. In: The Evolution of Nestling Begging: Competition, Cooperation and Communication (Wright, J.
\& Leonard, M. L., eds). Kluwer Academic, Dordrecht, The Netherlands, pp. $21-42$.

Price, K., Harvey, H. \& Ydenberg, R. 1996: Begging tactics of nestling yellow-headed blackbirds, Xanthocephalus xanthocephalus, in relation to need. Anim. Behav. 51, $421-435$.

Roulin, A. 2002: The sibling negotiation hypothesis. In: The Evolution of Nestling Begging: Competition, Cooperation and Communication (Wright, J. \& Leonard, M. L., eds). Kluwer Academic, Dordrecht, The Netherlands, pp. 107-126.

Roulin, A. 2004: Effects of hatching asynchrony on sibling negotiation, begging, jostling for position and within-brood food allocation in the barn owl, Tyto alba. Evol. Ecol. Res. 6, 1083-1098.

Roulin, A., Colliard, C., Russier, F., Fleury, M. \& Grandjean, V. 2008: Sib-sib communication and the risk of prey theft in the barn owl Tyto alba. J. Avian Biol. 39, 593-598.

Roulin, A., Dreiss, A., Fioravanti, C. \& Bize, P. 2009: Vocal sib-sib interactions: how siblings adjust signalling level to each other. Anim. Behav. 77, $717-725$.

SAS Institute Inc. 2007: JMP Statistics and Graphics Guide, Release 7. SAS Institute Inc., Cary, NC.

Smiseth, P. T. \& Moore, A. J. 2004: Signalling of hunger when offspring forage by both begging and selffeeding. Anim. Behav. 67, 1083-1088.

Smith, H. G. \& Montgomerie, R. 1991: Nestling American robins compete with siblings by begging. Behav. Ecol. Sociobiol. 29, 307-312.

Wiley, R. H. 2003: Is there an ideal behavioural experiment? Anim. Behav. 66, 585-588.

Wright, J. \& Leonard, M. L. 2002: The Evolution of Nestling Begging: Competition, Cooperation and Communication. Kluwer Academic, Dordrecht, The Netherlands. 